\title{
British Society of Interventional Radiology (BSIR) Inferior Vena Cava (IVC) Filter Registry
}

\author{
Raman Uberoi · Charles Ross Tapping • \\ Nicholas Chalmers • Victoria Allgar
}

Received: 7 July 2012/Accepted: 19 January 2013/Published online: 20 March 2013

(C) Springer Science+Business Media New York and the Cardiovascular and Interventional Radiological Society of Europe (CIRSE) 2013

\begin{abstract}
Purpose The British Society of Interventional Radiology (BSIR) Inferior Vena Cava (IVC) Filter Registry was produced to provide an audit of current United Kingdom (UK) practice regarding placement and retrieval of IVC filters to address concerns regarding their safety.

Methods The IVC filter registry is a web-based registry, launched by the BSIR on behalf of its membership in October 2007. This report is based on prospectively collected data from October 2007 to March 2011. This report contains analysis of data on 1,434 IVC filter placements and 400 attempted retrievals performed at 68 UK centers. Data collected included patient demographics, insertion and retrieval data, and patient follow-up.

Results IVC filter use in the majority of patients in the UK follows accepted CIRSE guidelines. Filter placement is usually a low-risk procedure, with a low major complication
\end{abstract}

Electronic supplementary material The online version of this article (doi:10.1007/s00270-013-0606-2) contains supplementary material, which is available to authorized users.

R. Uberoi $(\bowtie) \cdot$ C. R. Tapping

Department of Radiology, Oxford University Hospitals, John Radcliffe Hospital, Headington, Oxford OX3 9DU, UK

e-mail: raman.Uberoi@orh.nhs.uk

C. R. Tapping

Department of Radiology, Oxford University Hospitals,

Churchill Hospital, Old Road, Headington OX37LJ, UK

N. Chalmers

Department of Radiology, Manchester Royal Infirmary,

Oxford Road, Manchester M13 9WL, UK

V. Allgar

Hull and York Medical School, University of York, John

Hughlings Jackson Building, Heslington, York YO10 5DD, UK rate $(<0.5 \%)$. Cook Gunther Tulip (560 filters: $39 \%)$ and Celect (359 filters: $25 \%$ ) filters constituted the majority of IVC filters inserted, with Bard G2, Recovery filters, Cordis Trapease, and OptEase constituting most of the remainder (445 filters: $31 \%$ ). More than $96 \%$ of IVC filters deployed as intended. Operator inexperience $(<25$ procedure) was significantly associated with complications $(p<0.001)$. Of the IVC filters initially intended for temporary placement, retrieval was attempted in $78 \%$. Of these retrieval was technically successful in $83 \%$. Successful retrieval was significantly reduced for implants left in situ for $>9$ weeks versus those with a shorter dwell time. New lower limb deep vein thrombosis (DVT) and/or IVC thrombosis was reported in 88 patients following filter placement, there was no significant difference of incidence between filter types.

Conclusions This registry report provides interventional radiologists and clinicians with an improved understanding of the technical aspects of IVC filter placement to help improve practice, and the potential consequences of IVC filter placement so that we are better able to advise patients. There is a significant learning curve associated with IVC filter insertion, and when a filter is placed with the intention of removal, procedures should be in place to avoid the patient being lost to follow-up.

Keywords Inferior vena cava filter · Venous thromboembolism · Pulmonary embolus · Deep vein thrombosis

\section{Introduction}

Venous thromboembolism (VTE), including deep venous thrombosis (DVT) and pulmonary embolism (PE), is a 
common disorder that affects 100 per 100,000 individuals per annum [1]. The accepted standard treatment is full-dose anticoagulation, which is effective at reducing the risk of recurrent DVT and PE. Inferior vena cava (IVC) filters provide an alternative treatment for prevention of fatal pulmonary embolism in patients with contraindications to anticoagulation (short- or long-term) or when anticoagulation is ineffective [2]. In patients with short-term, or potentially reversible, contraindications to anticoagulation, current guidance states that retrievable IVC filters should be used in preference to permanent placement [2].

Retrievable IVC filters can be deployed for the period of time that a patient is at risk for PE but can then be removed to avoid the potential long-term complications [3]. The development of retrievable filters has expanded the use of IVC filters and led to an increase in the implantation of IVC filters in patients with a wider range of prophylactic indications [4]. All retrievable IVC filters can function as permanent filters if they are not removed. Several studies have indicated that only a small percentage of retrievable IVC filters (2-20\%) are removed and device related complications have been reported [4-8]. Recently the U.S. Food and Drug Administration issued a medical alert to address these considerations and emphasized filter removal as soon as protection from PE is no longer necessary [9]. Similarly, the Medicines and Healthcare products Regulatory Agency (MHRA) issued a warning that there had been a number of serious (but unspecified) complications associated with the attempted removal of filters left in situ for 3-18 months [10].

The decision to undertake a registry of IVC filter practice arose from concerns among British Society of Interventional Radiology (BSIR) members about the risks associated with filters coupled with a lack of knowledge of the fate of filters deployed with the intention of subsequent retrieval. The primary purpose of the BSIR IVC Filter Registry was to record and evaluate current practice in the United Kingdom. A secondary goal was to examine outcomes for patients, in particular complications associated with the insertion procedure, complications whilst the filter is in place, and the success of retrieval.

\section{Patients and Materials}

The Inferior Vena Cava Filter Registry, a web-based registry, was launched by the BSIR on behalf of its membership in October 2007. This report is mostly based on prospectively collected data from October 2007 to March 2011, although a small number of individuals inputted data retrospectively. All interventionalists, regardless of membership of BSIR, were invited to participate and complete the online dataset (electronic supplementary material) for all IVC filter placements and retrievals. Demographic, filter type, technical success and retrieval success, and complications were recorded. A separate form to record any follow-up visits that the patient may have undergone after the procedure was available. Two months before data analysis, all contributors were asked via email to complete any outstanding data.

This report contains analysis of data on 1,434 IVC filter placements and 400 attempted retrievals performed at 68 United Kingdom (UK) centers.

The intention of the registry was to capture follow-up data on all cases of at least 1 year. At least one follow-up record was available in $69 \%$. The registry was funded by the BSIR on behalf of its members.

\section{Statistical Analysis}

Statistical analysis was performed using SPSS version 16.0 (SPSS Inc., Chicago, IL). Multivariate regression analysis, $\chi^{2}$, and two-sided $t$ tests were performed. The level of statistical significance was set at $p \leq 0.05$.

\section{Results}

The mean age at placement was 63 (range 20-107) years. The peak in age distribution, irrespective of gender, was 70-74 years. There was no statistically significant difference in age distributions between the genders. The proportion of female patients is highest in the younger than 40 -year-old age group. There are relatively more men than women in the 55-64-year-old age group and a preponderance of women in the very oldest age groups, which is a reflection of the greater longevity of women. IVC filter usage and inputting of data into the registry increased over the lifespan of the registry with approximately 10 patients per month being added in 2007, 25 per month in 2008, 35 per month in 2009, 55 per month in 2010, and approximately and 70 per month in 2011 .

\section{Indication for Placement}

The vast majority of IVC filter placements were undertaken for recognized indications in accordance with CIRSE guidelines (see electronic supplementary material). The most commonly recorded indications were:

- Preoperatively for acute deep vein thrombosis (DVT)/ pulmonary embolus (PE) $(31 \%)$

- PE with contraindications to anticoagulation (24\%)

- Prophylaxis in high-risk patients (21\%)

Of the 95 patient entries with an "other" indication, only 34 have this as their sole indication and most of these 
can be accommodated in the recognized list of indications. A limited number of placements $(n=12)$ did not conform to guidelines; the most frequently cited was"DVT associated with malignancy but without associated PE or surgery" $(n=11 / 12)$ with "progression of DVT despite anticoagulation" comprising the remainder $(n=1)$.

\section{Placement Intention}

Over the life-span of the registry, there was a trend for increasing use of temporary filter placements $\left(\chi^{2}\right.$ analysis of trend over time; $p=0.014$; Fig. 1 ); $91 \%$ of placements in the 20-29-year-old age group were intended to be temporary compared with $19 \%$ in the 80-89-year-old age group. Those with presumed lifelong risk were more likely to have a permanent filter. All filters placed during pregnancy were intended for removal. Likewise, where there was clearly a short-term risk, such as preoperative patients with acute DVT/PE, the intention was for short-term filter placement in the majority of cases.

\section{Filter Types}

The majority of IVC filters deployed were of a retrievable type; this was even the case when the IVC filter was placed with the intention of leaving it permanently. The Cook Gunther Tulip filter was the most commonly placed IVC filter (39\%). The Cook Celect filter was the second most commonly placed device $(25 \%)$. Together, these two filters accounted for $64 \%$ of all the IVC filter placements recorded (Fig. 2). Bard G2, Recovery filters, Cordis Trapease, and OptEase accounted for the majority of the rest (31\%). There was a statistically significant trend for a proportionate increase in the use of the Celect filter over the lifetime of the registry $(p=0.003)$.
Procedure

The majority of procedures involved the use of the right femoral or right jugular approach (Fig. 3). The left jugular approach was very rarely used. Almost two-thirds of procedures were completed within $30 \mathrm{~min}$. Significantly more procedures took greater than $30 \mathrm{~min}$ when using the left femoral versus the right jugular approach $(2 \times 2$ contingency table; $p=0.014$ ).

The vast majority of filters were placed in an infra-renal (92\%) or juxta-renal location (3.5\%). Of the 53 suprarenal filter placements, 27 were for IVC thrombosis and 13 for pregnancy with no clear reason for choosing a suprarenal location in 7 and data in 6. Placement and retrieval of IVC filters was in accordance with the manufacturer's instructions for use.

\section{Outcomes}

\section{Implantation}

More than $96 \%$ of filters deployed as intended. Failure to deploy as planned occurred in $3.3 \%$ of cases $(48 / 1,434)$. The explanation in most cases was tilting, sometimes due to unexpected anatomical variations. Failure to open properly or failure to deploy at the intended site was reported in 11 cases (9 Tulip, 2 Simon Nitinol). The procedure was abandoned in only two cases. In one case, a Cordis OptEase device was retrieved immediately after placement because of pain. In the other, deployment was abandoned due to dilated IVC.

Multivariate analysis revealed independent factors associated with a technically successful procedure were younger age $(p=0.022$, odds ratio $(\mathrm{OR})=1.017,95 \%$ confidence interval $(\mathrm{CI})=1.002-1.031)$ and type of device $(p<0.001)$ :
Fig. 1 Placement intention versus time (used with permission from Dendrite Clinical Systems, Henley-onThames, Oxfordshire, UK)

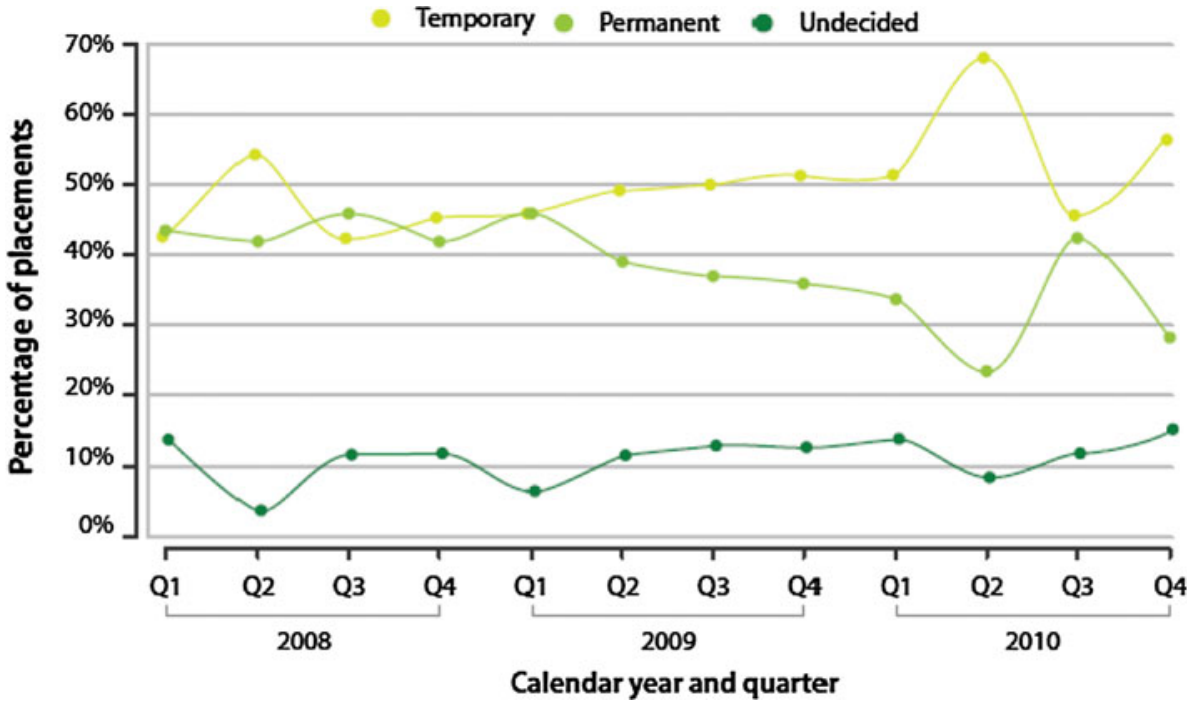


Fig. 2 Type of IVC filter used (used with permission from Dendrite Clinical Systems, Henley-on-Thames,

Oxfordshire, UK)
Fig. 3 Approach for IVC filter insertion (used with permission from Dendrite Clinical Systems, Henley-on-Thames, Oxfordshire, UK)
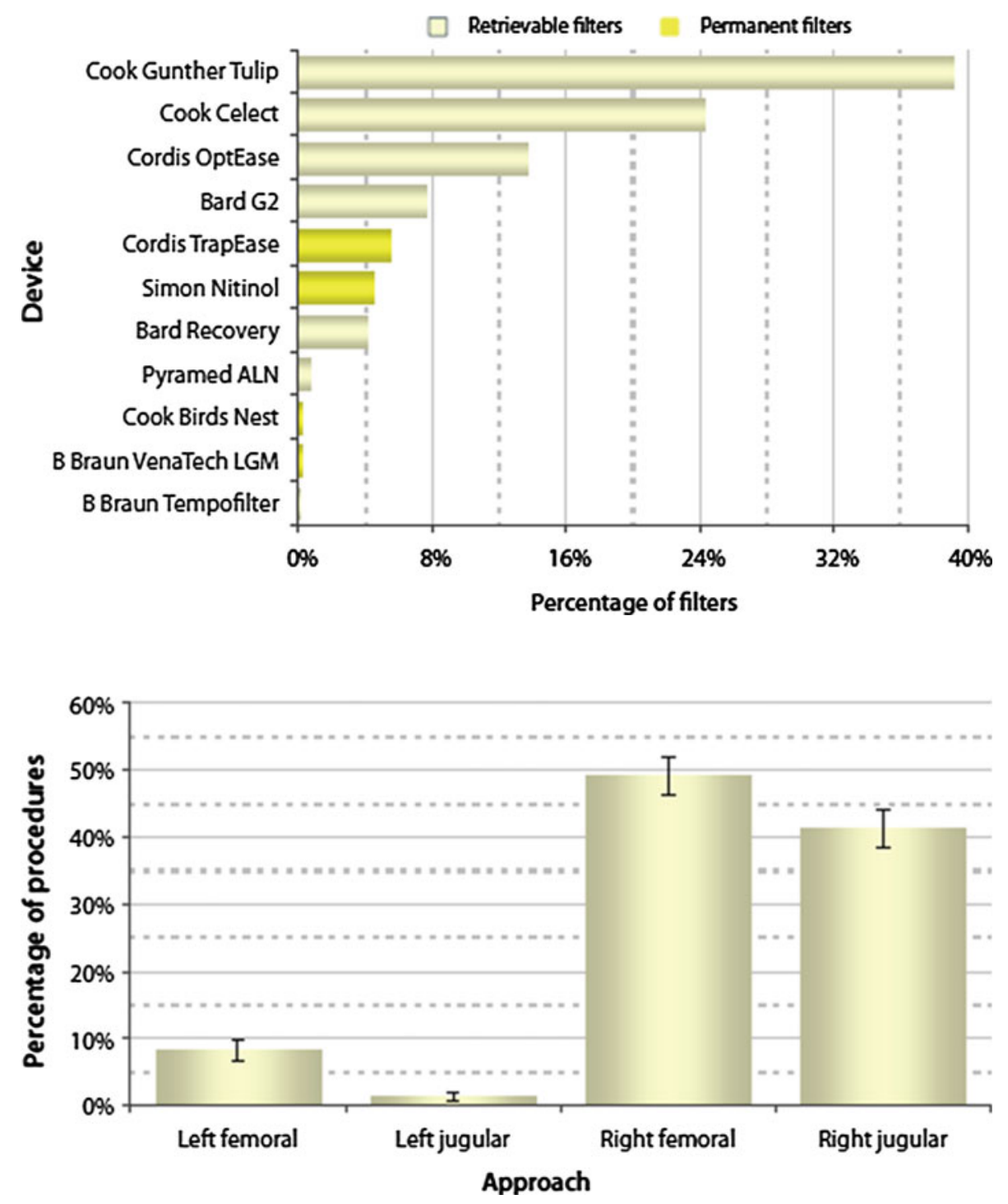

the Bard G2 IVC filter $(p=0.002, \mathrm{OR}=15.311,95 \%$ $\mathrm{CI}=2.627-89.224)$, Bard Recovery IVC filter $(p=0.017$, $\mathrm{OR}=11.11,95 \% \mathrm{CI}=1.544-79.951)$, and the Cook Celect IVC filter $(p=0.019, \mathrm{OR}=5.012,95 \% \mathrm{CI}=1.307-$ 19.255) were the most successfully placed.

Filter Tilting at Deployment

Of the 1,434 IVC filters placed, 1,033 (72\%) were centralized, 190 (13\%) were tilted, 49 (3\%) were seen to abut the IVC wall, and 162 (12\%) were unspecified. The Cook Gunther Tulip and Celect filters were associated with tilting, or apex abutting the caval wall, in more than $20 \%$ of placements. Tilting was less frequently reported with the Cordis TrapEase and OptEase and the Bard G 2 device. Tulip and Celect filters deployed via the left femoral approach were significantly less likely to be centralized than those deployed via the right femoral approach
( $p=0.012)$ or via the right jugular approach $(p=0.02)$. These findings suggest that, if the right femoral approach is not available, a right jugular approach is probably preferable to a left femoral approach.

Dwell Time

The duration of placement for each of the various filter models recorded in the registry where retrieval was attempted differed significantly:

- Bard G 2 median dwell time 77 (range 34-154) days

- Bard Recovery median dwell time 77 (range 28-166) days

- Cook Celect median dwell time 32 (range 18-66) days

- Cook Gunther Tulip median dwell time 39.5 (range 22-101) days

- Cordis OptEase median dwell time 12 (range 2-45) days 
The duration of placement was significantly shorter for the Cordis OptEase filter $(p \leq 0.001)$ compared with any of the other filters, in keeping with differences in the Instructions for Use.

\section{Retrieval}

Of 721 filters placed with the intention of retrieval, there was no retrieval information on 207 (29\%). Of the remaining 514, retrieval was attempted in $415(81 \%)$ and was technically successful in $83 \%$. The reasons for not retrieving the remaining $99(19 \%)$ included clinical deterioration and caval thrombosis. Many of the failed to retrieve filters failed to be retrieved within the dwell time suggested by the manufacturer (Table 1). Follow-up data indicate that this group has poor long-term survival reflecting significant clinical deterioration. Retrieval success diminished with duration of implantation. Filters that had been deployed for more than 9 weeks ( $>62$ days) were significantly less likely to be successfully retrieved compared with those with a shorter duration of implantation $(p=0.001)$. This is most likely to be due to incorporation of the device in the caval wall, IVC thrombosis, and penetration of the caval wall by the filter legs $(p<0.001)$. There was no significant difference in retrieval success of different filter types; Bard IVC filters achieved the highest success rates, despite the longest median dwell time of 77 days. For the filters where there was no initial decision on the intended duration of filter placement, $34 \%$ were retrieved. Retrieval was usually a quick procedure; $68 \%$ took less than $30 \mathrm{~min}$. Retrieval was associated with a limited number of minor complications and no serious complications. In the 25 pregnant women reported in the registry, there was no recorded attempt at retrieval in 2 patients, failure to retrieve in 6 , and successful retrieval was recorded in only 12 patients; the retrieval data were missing for the other 5 entries, suggesting that, in this subgroup, the overall retrieval rate was less than $50 \%$. Significant tilting, to the extent that the filter head was abutting the caval wall, was a frequently indicated cause of failure to retrieve the filter.

Multivariate analysis revealed that independent factors associated with no attempt at IVC filter retrieval were older age $(p<0.001, \mathrm{OR}=0.967,95 \% \mathrm{CI}=0.958-0.975), \mathrm{DVT} / \mathrm{PE}$ and limited cardiopulmonary function $(p=0.009$, OR $=$ $2.787,95 \% \mathrm{CI}=1.296-5.992)$, evidence of preoperative PE $(p \leq 0.001, \mathrm{OR}=4.531,95 \% \mathrm{CI}=3.144-6.529)$, and in the group "prophylaxis in high-risk groups" $(p<0.001$, $\mathrm{OR}=3.817,95 \% \mathrm{CI}=2.548-5.719$ ).

A total of 190 (13\%) filters were tilted post deployment and $49(3 \%)$ were seen to abut the IVC wall. There was no significant difference between these and centralized IVC filters and a successful retrieval $(p=0.643)$.

\section{Retrieval Complications}

Reported complication rates are in the range $0.0-16.7 \%$ on a device-by-device basis; on review of the detailed description data on the recorded filter complications, it transpires that the majority of these were not true retrieval complications. There were three caval tears reported, which were not associated with adverse clinical consequences and one dissection of the internal jugular vein. There were three mechanical/structural failures of the retrieval device of the Cook Gunther Tulip filter with no significant clinical sequelae, and retrieval was successfully achieved using a modified technique. The majority of the "other" reported complications were attributed to tilting of the filter, strut perforation, or thrombosis. Multivariate analysis revealed that independent factors associated with retrieval complications were: older age $(p=0.024$, OR $=$ $0.975,95 \% \mathrm{CI}=0.953-0.997)$ and anticoagulation use $(p=0.046, \mathrm{OR}=0.385,95 \% \mathrm{CI}=0.151-0.982)$.

\section{Postdeployment Complications}

In general, filter complication rates were low, with an average complication rate of $3.5 \%$. There were, however, two reported major complications involving surgical removal of the filter. Pain associated with caval perforation led to surgical removal of a Cook Celect filter in one case. A further filter (Cook Gunther Tulip) required surgical removal following penetration through the caval wall during insertion. A third filter was removed at laparotomy performed for other reasons: penetration of the caval wall was noted at surgery.

Funnel plot analysis of overall postprocedure complications and filter-specific complications identified the rates associated with the Bard G 2 filter as lying outside $99.9 \%$ control limits (average rate $=6.4 \%$ ). The outcomes for all other filter types fell within both $99.9 \%$ control limits of the funnel plot (Fig. 4).

\section{Filter Structural Failure}

No instances of fracture or significant structural failure were reported.

\section{Other Postdeployment Complications}

The 27 filter complications described as "other" (18 patients) comprised 6 cases of IVC thrombosis, 7 of DVT, 3 possible puncture site complications and 11 apparently unrelated complications. No filter complications were reported with any of the permanent devices.

DVT is a known risk of IVC filter placement. The rate identified in this series was low $<1 \%(14 / 1,434)$, which 
Table 1 Failed retrieval of filter by make/model and \% of failures within manufacturer timescale

NB Dwell time as suggested by the manufacturer ${ }^{\mathrm{a}} \mathrm{B}$ Braun Tempo filter $<12$ weeks, Bard G2 unspecified indwell time, Bard Recovery not specified, Cook Celect suggested $<67$ weeks, Cook Gunther Tulip suggested $<20$ days, Cordis OptEase 23-day indwell time, Pyramed ALN suggested $<25$ months, Permanent filters B Braun VenaTech LGM Permanent, Cook Birds Nest Permanent, Cordis TrapEase Permanent, Simon Nitinol Permanent

\begin{tabular}{|c|c|c|c|}
\hline Filter Type & $\begin{array}{l}\text { Total number of } \\
\text { failures }\end{array}$ & $\begin{array}{l}\text { Failures within } \\
\text { timescale }^{\mathrm{a}}\end{array}$ & $\begin{array}{l}\% \text { failure within } \\
\text { timescale }\end{array}$ \\
\hline $\begin{array}{l}\text { B Braun Tempofilter IVC filter } \\
\text { (retrievable) }\end{array}$ & 0 & 0 & 0 \\
\hline $\begin{array}{l}\text { B Braun VenaTech LGM IVC } \\
\text { filter }\end{array}$ & 0 & 0 & 0 \\
\hline Bard G2 IVC filter & 42 & 42 & 100 \\
\hline $\begin{array}{l}\text { Bard Recovery IVC filter } \\
\text { (retrievable) }\end{array}$ & 19 & $\begin{array}{l}\text { Not specified by } \\
\text { manufacturer }\end{array}$ & 0 \\
\hline Cook Birds Nest IVC filter & 0 & 0 & 0 \\
\hline $\begin{array}{l}\text { Cook Celect IVC filter } \\
\text { (retrievable) }\end{array}$ & 138 & 134 & 97.1 \\
\hline $\begin{array}{l}\text { Cook Gunther Tulip IVC filter } \\
\text { (retrievable) }\end{array}$ & 151 & 38 & 25.2 \\
\hline $\begin{array}{l}\text { Cordis OptEase IVC filter } \\
\text { (retrievable) }\end{array}$ & 47 & 39 & 83 \\
\hline Cordis TrapEase IVC filter & 0 & 0 & 0 \\
\hline $\begin{array}{l}\text { Pyramed ALN IVC filter } \\
\text { (retrievable) }\end{array}$ & 8 & 7 & 87.5 \\
\hline Simon Nitinol IVC filter & 0 & 0 & 0 \\
\hline Missing data & 10 & 0 & 0 \\
\hline
\end{tabular}

Fig. 4 Complication rate associated with filter type (used with permission from Dendrite Clinical Systems, Henley-onThames, Oxfordshire, UK)

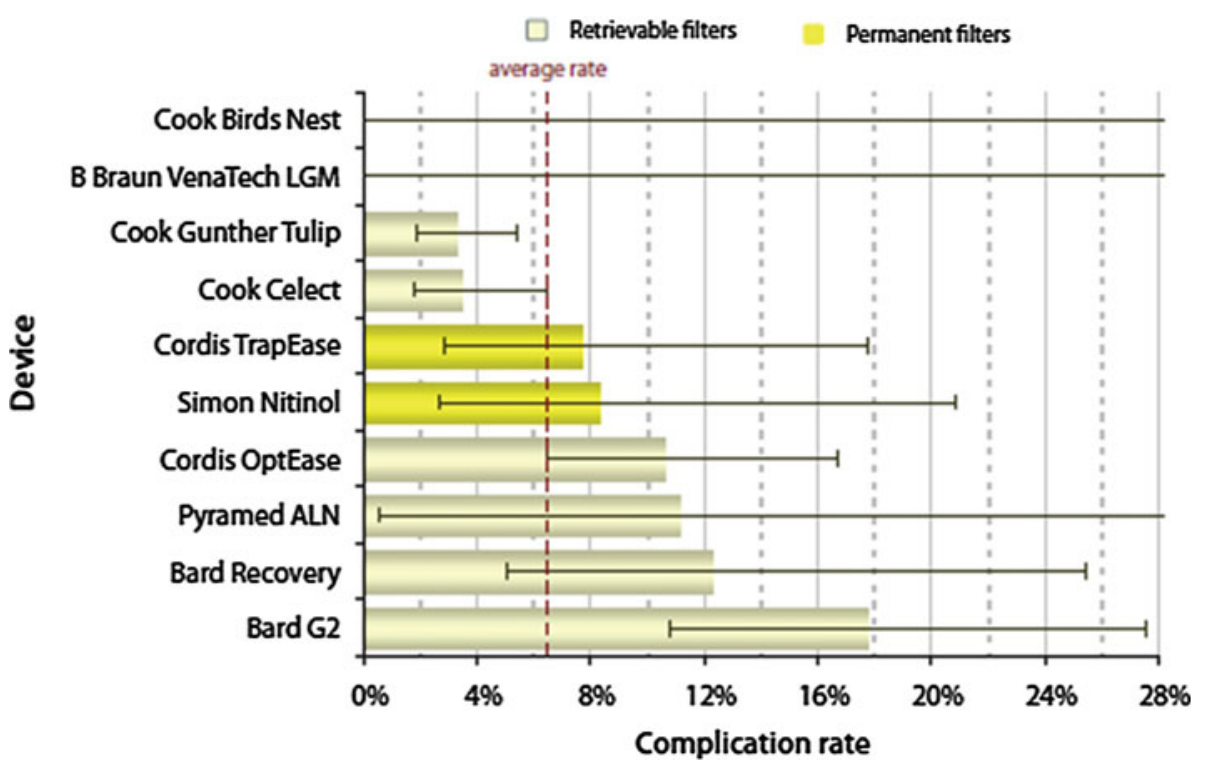

may reflect under-reporting of this complication. There are differences between the postprocedure rates of DVT for Cook Celect versus Cordis OptEase (2-sided Fisher's exact test; $p=0.004$ ) and for Cook Gunther Tulip versus Cordis OptEase (2-sided Fisher's exact test; $p=0.002$ ), indicating a higher rate of thrombosis associated with the Cordis OptEase filter. Inexperience (performing $<25$ filter deployments) was statistically related to more complications $(p<0.001)$.

Multivariate analysis revealed independent factors associated with complications were a left internal jugular vein approach $(p<0.001, \mathrm{OR}=3.742,95 \% \mathrm{CI}=1.912-7.373)$, anticoagulation $(p=0.037, \mathrm{OR}=0.62,95 \% \mathrm{CI}=0.396$ 0.973 ), and inexperience (operator grade: $<10$ previous deployments $(p \leq 0.001$, OR $=0.255,95 \%$ CI $=0.099$ $0.551)$ and $10-25$ previous deployments $(p \leq 0.001$, $\mathrm{OR}=0.073,95 \% \mathrm{CI}=0.019-0.273)$ ).

\section{Long-term Complications}

Filter Perforation of the Caval Wall Perforation was more commonly reported with the Bard Recovery and G 2 filters than with other devices. Perforation was the reason 
for failure to retrieve the filter in five cases. In one case, a filter leg was noted to be located within the aortic wall. It was retrieved without adverse consequences. No instances of symptomatic penetration of adjacent organs were recorded in the registry. No perforations were seen with the Cordis filters. Perforation associated with each filter type was:

- $\quad$ Bard G2 $14 \%$

- Bard Recovery $10 \%$

- Cook Gunther Tulip $2 \%$

- All others $<0.3 \%$

Filter Migration Contributors were asked to report migrations of $>10 \mathrm{~mm}$. A total of nine migrations were reported: four with Bard G 2 filter, three with the Cook Celect filter, and one each with the Bard Recovery and Cordis OptEase filters. Six episodes of migration occurred immediately postdeployment. In one case, caudal migration was associated with failure to retrieve the filter. One filter (Celect) deployed in a suprarenal location, migrated to the intrahepatic IVC, close to the right atrium and was retrieved. Migrations were noted in both cranial and caudal directions. There were no cases of embolization of IVC filters to the heart or pulmonary arteries.

Pulmonary Embolism and IVC or Lower Limb Thrombosis Pulmonary embolism (PE) was reported in 16 cases during the follow-up period, and although this was reported to be the cause of death in 6 , this was not supported by objective evidence in most instances following telephone consultation. Multivariate analysis revealed only one independent variable associated with recurrent PE, which was location: suprarenal $(p=0.041, \mathrm{OR}=373.636,95 \%$ $\mathrm{CI}=1.265-519.241)$.

New lower limb DVT and/or IVC thrombosis was reported in 88 cases in total. Although immediate outcomes following filter placement showed some differences in DVT rates between devices, there were no statistically significant differences in the incidence of DVT between devices during the 3 years of follow-up (Fig. 5). Multivariate analysis revealed independent factors associated with recurrence of DVT were older age ( $p=0.046$, $\mathrm{OR}=0.980,95 \% \mathrm{CI}=0.961-1.000)$ and placement intention - permanent $(p=0.013$, OR $=1.222,95 \%$ $\mathrm{CI}=1.001-1.411)$. When a filter was removed, there was no greater risk of pulmonary embolus than in those patients in whom the filter had been left in situ.

Multivariate analysis revealed complications at 12 months after insertion were related to older age ( $>75$ years; $p=0.02$, OR $=0.981,95 \%$ CI $=0.969-$ $0.993)$, temporary IVC filter not removed at 1 year $(p=0.002$, OR $=0.407,95 \% \mathrm{CI}=0.234-0.711)$ and juxtarenal location $(p=0.02, \mathrm{OR}=0.333,95 \% \mathrm{CI}=$ 0.132-0.838). The use of the Cordis TrapEase IVC filter ( $p=0.008$, OR $=8.216,95 \%$ CI $=1.720-39.244)$ was associated with increased complications.

Mortality The large group of patients who had a filter placed with the intention that it would be a permanent filter appear to have an elevated in-hospital mortality rate compared with those who had a filter inserted with the intention that it would be temporary $(12.3 \%$ vs. $4.3 \%$ respectively; Table 2). However, the difference of mortality, both in-hospital and at 30 days, between temporary and permanent placements was probably due to difference in severity of the underlying disease.

The high mortality $(257 / 1,434 ; 18 \%)$ at 1 year where no retrieval was attempted was probably due to deterioration in the patient's underlying clinical condition. There was no significant difference in mortality between patients who had failed versus successful retrieval.

\section{Discussion}

The BSIR IVC Filter Registry has provided a substantial body of information with regard to the current status of IVC filter usage in the UK. These data provide useful information to improve current practice and allow us to take steps to improve patient care.

IVC filters can broadly be divided into two groups: retrievable and permanent. Instructions for use state that retrievable IVC filters can be left in place permanently if desired. As a consequence, even where the intention was to leave the filter in place permanently, a retrievable filter was utilized in the majority of cases $(73 \%)$. This indicates that operators have confidence in the permanent deployment of retrievable filters. Convertible filters were recently introduced and can be changed from a filter configuration to a stent, once the filtering capability is no longer required. Following the introduction of convertible filters to the UK, contributors were given the opportunity to record this as an intention. In the event, no convertible filters were used.

The data indicated a significant learning curve associated with IVC filter insertion. Operators with experience of $<25$ IVC filter insertions were statistically more likely to have a complication. Although these were mostly minor, it is important for interventional radiologists to be aware of these and to receive appropriate training when using a new device. Furthermore, results suggest that, if the right femoral approach is not available, a right jugular approach is probably preferable to a left femoral approach and should be adopted in most instances.

The registry demonstrated an increased use of temporary IVC filters over the time of the registry, which may 
Fig. 5 DVT-free rate post-IVC filter insertion (used with permission from Dendrite Clinical Systems, Henley-onThames, Oxfordshire, UK)

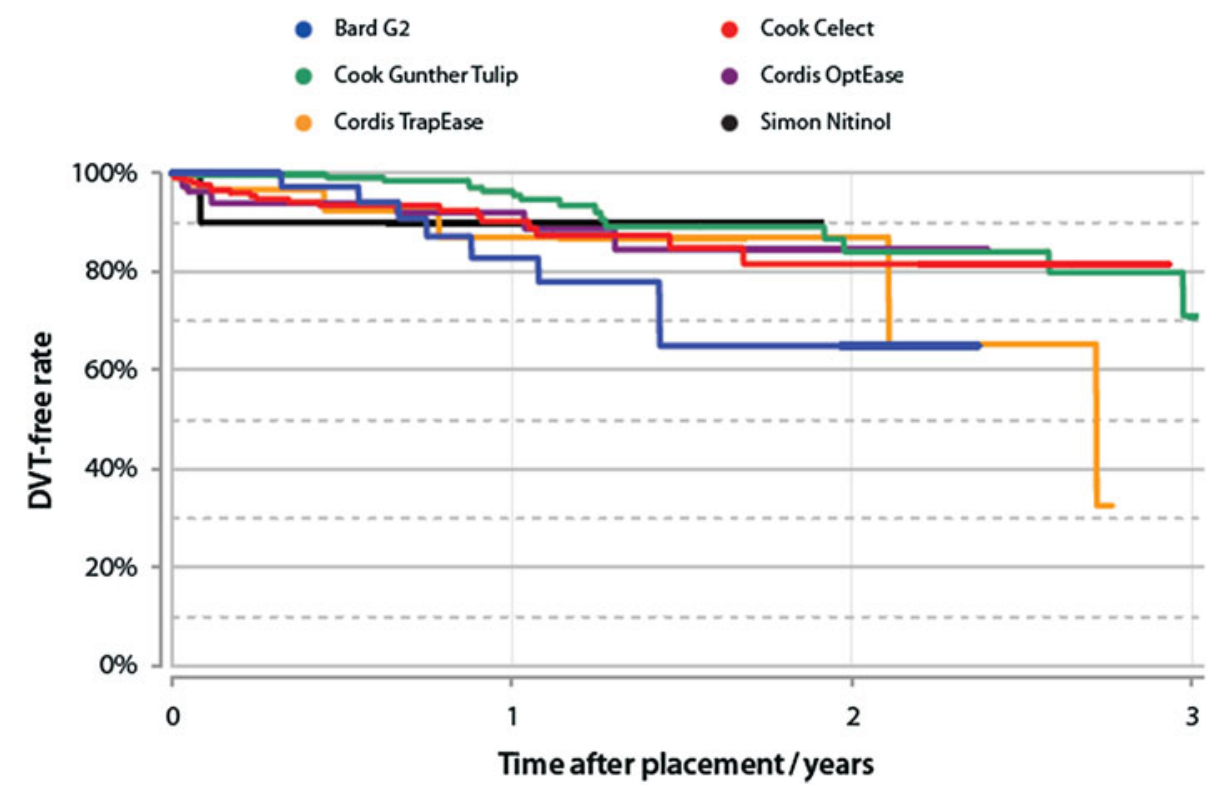

Table 2 Thirty-day mortality and \% of deaths by IVC filter type

\begin{tabular}{lrcc}
\hline Make of device & Total & Deaths & $\%$ \\
\hline B Braun Tempofilter IVC filter (retrievable) & 1 & 0 & 0 \\
B Braun VenaTech LGM IVC filter & 2 & 1 & 50 \\
Bard G2 IVC filter & 95 & 2 & 2.1 \\
Bard Recovery IVC filter (retrievable) & 54 & 1 & 1.9 \\
Cook Birds Nest IVC filter & 3 & 0 & 0 \\
Cook Celect IVC filter (retrievable) & 325 & 9 & 2.8 \\
Cook Gunther Tulip IVC filter (retrievable) & 535 & 10 & 1.9 \\
Cordis OptEase IVC filter (retrievable) & 182 & 5 & 2.7 \\
Cordis TrapEase IVC filter & 88 & 1 & 1.1 \\
Pyramed ALN IVC filter (retrievable) & 45 & 3 & 6.7 \\
Simon Nitinol IVC filter & 57 & 3 & 5.3 \\
Missing data & 46 & 0 & 0 \\
\hline
\end{tabular}

indicate an increasing reluctance to leave filters permanently or an increasing confidence in the retrievable devices for permanent or temporary use. The high proportion of temporary IVC filters (inserted with an intention that they would be temporary) in young patients reflects clinicians' reluctance to leave foreign materials permanently in younger patients. Less than $50 \%$ of filters inserted into pregnant women were confirmed to be removed. In some cases, retrieval may be impossible due to marked tilting of the filter in late pregnancy or during labor. Other cases may have been lost to follow-up. No attempt at retrieval for this group of patients should be considered inacceptable practice. The decision to implant a permanent IVC filter was related to the severity of the underlying condition and/or significant comorbidities. Those patients with severe underlying comorbidities and/or a poor prognosis were more likely to be considered for a permanent filter, presumably to limit the number of repeated interventions and hospital admissions in the later stages of their disease. Furthermore, the high mortality in patients considered for a permanent IVC filter suggests that a rapid decline in a patient's health is related to inserting a permanent filter.

Most filters are intended to be located so that the apex lies centrally within the vena cava and some have design features to promote centring. The VenaTech Braun LGM filter has a number of parallel struts that lie along the caval wall to ensure centring. No tilting was observed with this filter in the few deployments that were reported. The Cordis filters also have parallel struts, but these are less rigid, so distortion and tilting can occur. Tilting was more frequently observed with the Cook filters, which have a conical shape. Tilting may occur at the moment of release of the filter from the delivery system if the delivery system is angulated in relation to the axis of the cava. It also may occur during detachment of the apical hook from the delivery system after jugular deployment of the Cook filters, especially with inexperienced hands and from a left IJV approach. Although one would expect centralized filters to be associated with a higher rate of successful retrieval, this effect has not reached statistical significance in the registry. Contrary to expectation, retrieval success of the Cook Celect and Tulip filters was unrelated to filter tilting at deployment, with success rates of approximately $80 \%$ for all orientations. It is likely that tilting did not occur at the time of deployment, but it occurred at a later date. For the other filters in this registry, tilting was 
associated with a lower success rate of filter retrieval $(p=0.004)$.

There was a relationship between the rate of successful retrieval and the number of retrievals attempted. Highvolume centers tended to achieve a better than average success rate. Older patients ( $>80$ years) and the presence of significant comorbidity has been shown to be associated with a significantly reduced probability for attempted retrieval [11]. Retrieval was statistically more successful in our cohort if attempted $<9$ weeks ( $<62$ days) from insertion. A time interval of $>90$ days between implantation and attempted retrieval also was associated with greater retrieval failure (OR 19.8, $p=0.009$ ) in another recent study [11]. Interestingly, in those cases where there was retrieval failure a high proportion were within the time period defined by the manufacturers for retrieval, i.e., with the Bard G2 (100\%), Cook Celect (97\%), Cordis Optease (83\%), and Pyramed ALN (87.5\%; Table 1). This suggests that regardless of suggested dwell times IVC filters should be removed as soon as practically possible to reduce not only associated complications but also to reduce failure of retrieval rate.

The mechanism of filter retrieval varies between manufacturers. The Bard devices rely on trapping the apex of the filter in a cone. The Cook and Cordis filters require snaring of a small hook located on the apex (Cook) or base (Cordis) of the filter. Snaring the hook is difficult if the filter is tilted or the hook is embedded in the caval wall. Nonstandard retrieval techniques, such as using intraarterial forceps, balloons to displace the apex, or wire loops passed through the filter, were employed in isolated cases when the apex could not be snared. With the exception of ALN, for which numbers were very small, the Bard filters combined had the highest rate of retrieval success, despite having the longest in-dwell times, but individually this did not reach statistical significance.

The use of IVC filters has grown steadily over the lifespan of the registry and is predicted to continue to increase. Generally, the most common indication for IVC filter insertion is $\mathrm{PE}$ with a contraindication to anticoagulation. However, we found that the most common reason for IVC filter insertion was preoperatively for DVT/PE, suggesting a better appreciation of clinicians for prophylactic IVC filter insertion. Furthermore, the prophylactic use of filters in patients affected by trauma has increased recently, especially with the availability of retrievable filters [3, 12]. However, in many series, the rate of retrieval of these filters has been low (30\%) [13]. Of 721 filters in the registry placed with the intention of retrieval, there was no retrieval information on 207 . We do not know whether or not these filters were removed as intended. It is probable that some filters were placed with the intention of retrieval, but the patients were not referred back to the radiology department for this procedure and the filters were unintentionally left in place permanently. We believe that it is important that the radiologist who places a filter with the intention of retrieving it takes responsibility for ensuring that the patient is recalled for retrieval at a suitable interval. This is probably most easily achieved by prospectively arranging for patients to return for retrieval on the local hospital Radiology Management Systems (RMS). A recent study by Lee et al. [14] employing a radiologist-led retrieval algorithm encouraging clinicians to request IVC filter removal postinsertion did not find any statistical improvement in numbers of filter removed [14]. However, they noted that the radiology-led approach improved follow-up and documentation, ensuring that a clinical decision was made about how long the IVC filter was required and whether retrieval should be attempted, thus ensuring that patients were not lost to follow-up [14]. Another group has demonstrated improved IVC filter removal rates employing a mailing system to contact patients when it is time to remove their filter [15].

One of the concerns that the registry sought to address was whether retrievable filters inserted for permanent placement were as safe as filters specifically designed for permanent placement. A lower rate of filter-specific complications was observed with permanent than with retrievable filters, but overall complications were not statistically significantly different, indicating that the current UK practice of using temporary filters as permanent filters is safe. Furthermore, using temporary retrievable filters as permanent filters may allow removal if a complication arises at a later date.

The commonest filter complications consist of filter migration and caval wall perforation, which may have no clinical consequences. However, filter struts that penetrate the caval wall may occasionally cause symptoms due to penetration of adjacent organs. Caval wall penetration by IVC filter struts has been shown by another group to be correlated with retrieval failure, and this group also found that the Filter hook/IVC orientation was significantly related to successful retrieval [16]. Overall perforation rates were low in our series, but in the absence of systematic CT follow-up, perforation is likely to have been underreported. It is likely that asymptomatic perforation of the caval wall occurs with several filter types, and in the absence of a CT scan this is not easy to quantify. Durack et al. demonstrated that strut penetration of the caval wall is the rule rather than the exception and also that complications associated with it can be significant [17].

PE appears to be a rare event following IVC filter placement; however, the possibility of underreporting should be borne in mind. We found that when a filter was removed, there was no greater risk of PE than in those patients in whom the filter had been left in situ. This 
finding has been demonstrated by others who showed that new or recurrent PE was rare after retrieval of an IVC filter but was most likely to occur in patients who had severe DVT during filter implantation and/or in patients with a DVT that remained at the time of filter retrieval [18]. Recurrent DVT is a known risk factor following IVC filter placement. The proportion of these that can be attributed to the presence of the filter is speculative. A large thrombus in the filter might indicate successful trapping of a potentially fatal thrombus and, therefore, could be an indication that the filter has been effective. Following the PREPIC study, there is a known increased risk of DVT following the placement of IVC filters [19]. This is probably due to local trauma at the insertion site and/or change in flow dynamics in the IVC following filter placement. Alternatively, the filter itself may be a nidus for thrombus formation. Indeed, in some cases, thrombus was identified on the cranial side of the filter. There was no statistically significant difference in DVT rates found in this registry between those patients who had successful filter retrieval compared with those who had their filters left in place $(p=0.632)$.

The average in-hospital mortality rate following IVC filter placement is $8.1 \%$, indicating that this patient population is overall a high-risk group of individuals with most probably their mortality risk from underlying existing conditions.

One-year follow-up data was considered to be a very important aspect of this registry, and registrants were encouraged to complete the follow-up forms by regular email reminders. Despite this, 1-year follow-up data were missing in a substantial number of registered cases. Forty percent of patients who were discharged alive from the hospital following filter placement had no follow-up recorded in the registry.

Overall, the numerous contributors to this registry are to be congratulated on helping to produce the largest prospective collection of data on the practice of IVC filters placement in the world, which will help to direct future practice in the United Kingdom. There are several caveats, however, that we feel are important to discuss. First, not all UK centers participated in data collection and the proportion of cases registered by participating centers is not known. There was no independent external data monitoring and verification performed, and there were some instances of differences in interpretation of certain data items between participants. There was no systematic clinical or imaging protocol follow-up regime employed; thus, data on long-term filter integrity, migration, and caval wall perforation is derived from clinically driven investigations. These points detract from the quality of some of the data analysis and limit our confidence in some of the conclusions.

\section{Conclusions}

IVC filter use in the UK in the vast majority of patients follows accepted guidelines (CIRSE). IVC filter placement is normally a low-risk procedure, with a low major complication rate of $<0.5 \%$. This report provides interventional radiologists with an improved understanding of the technical and clinical aspects of IVC filter placement and will help to improve practice and reduce the potential negative consequences of IVC filter placement so that we are better able to advise patients and referrers.

\section{Recommendations}

- If right femoral access is not available for the placement of an IVC filter, a right internal jugular vein approach should be used when possible.

- When an IVC filter has been placed with the intention of removal, procedures should be put in place to avoid the patient being lost to follow-up. This could be done by simply booking an appointment on the Radiology Information System to have the IVC filter removed.

- Filterretrievalismostsuccessfulbefore9 weeksfollowing deployment and patients should be booked for removal within this timeframe if clinically appropriate.

\section{Contributors}

Addenbrooke's Hospital, Cambridge

Andrew Winterbottom

Aintree University Hospital, Liverpool

Aldo Camenzuli

University Hospital Aintree

Elizabeth O'Grady

Altnagelvin Area Hospital

Deirdre Campbell

Ayr Hospital

Jean-Pierre Charon

Barts \& the Royal London

Deborah Low

Barts and the Royal London Hos

Matthew Matson

Bradford Teaching Hospitals Foundation Trust

Carolyn Jackson

Churchill Hospital, Oxford

Philip Boardman

City Hospital, Birmingham

Mark Moss

Colchester General Hospital

Arun Joachim Sebastian

Cumberland Infirmary, Carlisle 
John Michael Harry Edge

Cumberland Infirmary

Jonathan Poels

Derriford Hospital, Plymouth

Patrick Sparrow

Diana Princess of Wales Hospital, Grimsby

Ayman Elsayed

Diana, Princess of Wales Hospital,

Richard W J Harries

East Sussex Hospitals NHS Trust

Neil Barlow

Freeman Hospital, Newcastle-upon-Tyne

Ralph Jackson

Frimley Park Hospital, Surrey

Andrew Hatrick

Gartnavel General Hospital, Glasgow

Sivanathan Chandramohan

Gartnavel General Hospital

Richard D Edwards

Gartnavel General Hospital

Christopher Hay

Gartnavel General Hospital

Ram Kasthuri

Gartnavel General Hospital

Jon Moss

Gartnavel General Hospital

Iain Robertson

Gartnavel General Hospital

Reddi Yadavali

Glan Clwyd Hospital, Rhyl

Charles McConnell

Glan Clwyd Hospital - North Wales

Elaine Moss

Hairmyres Hospital, East Kilbride

Samuel Millar

Hairmyres Hospital

Cliff Murch

Harrogate Health Care NHS Trust

David Scullion

Hull Royal Infirmary

Duncan Ettles

Hull Royal Infirmary

Raghuram Lakshminarayan

Hull Royal Infirmary

Graham John Robinson

Hull Royal Infirmary

Paul Scott

Hull Royal Infirmary

Vivek Shrivastava

Ipswich Hospital

Gary Picken

Ispwich Hospital
Patrick Whitear

John Radcliffe Hospital, Oxford

Susan Anthony

John Radcliffe Hospital, Oxford

Mark Bratby

John Radcliffe Hospital

Raman Uberoi

Kingston Hospital NHS Trust

Colin Eric Campbell Todd

Leeds Teaching Hospital

Chris Hammond

Leeds Teaching Hospitals Trust

David Kessel

Leeds Teaching Hospitals Trust

Tony Nicholson

Leeds Teaching Hospitals Trust

Jai Patel

Leeds Teaching Hospitals Trust

Simon McPherson

Leeds Teaching Hospitals Trust

Gillian Procter

Leeds Teaching Hospitals

Sapna Puppala

Leicester Royal Infirmary

Keith Blanshard

Lister Hospital, Stevenage

Christopher M P King

Manchester Royal Infirmary

Nicholas Chalmers

Manchester Royal Infirmary

Gerard Joachim Murphy

Medway Maritime Hospital, Gillingham

Zeljko Bosanac

Mid Yorkshire Hospitals NHS Trust

James Lenton

Mid Staffordshire NHS Foundation Trust

David Wells

New Cross Hospital, Wolverhampton

Jules Dyer

Norfolk \& Norwich Hospital

Simon Girling

North Bristol NHS Trust

Lyn Jones

Northampton General Hospital

Ramita Dey

Northampton General Hospital

Davis Thomas

Northern General Hospital, Sheffield

Steven Thomas

Papworth Hospital

Deepa Gopalan

Pinderfields Hospital, Wakefield 
Kanwar Gill

Pinderfield

Rishya Ranalingam

Princess Royal University Hospital, Orpington

Richard Carver

Queen Alexandra Hospital, Portsmouth

John Langham Brown

Queen Alexandra Portsmouth

Simon Coles

Queen Elizabeth Hospital, Gateshead

Colin Nice

Queen Elizabeth, Gateshead

Grace Timmons

Rotherham NHS Foundation Trust

Paul Spencer

Royal Berkshire NHS Foundation Trust

Farhan Ahmad

Royal Berkshire NHS Foundation Trust

Matthew Gibson

Royal Bolton Hospital

James Lay

Royal Bournemouth Hospital

Terry Stephen Creasy

Royal Bournemouth Hospital

John Oakes

Royal Bournemouth Hospital

David F C Shepherd

Royal Cornwall Hospital, Truro

John Hancock

Royal Derby Hospital

Peter Bungay

Derbyshire Royal Infirmary

Mario De Nunzio

Derbyshire Royal Infirmary

Graham Pollock

Royal Gwent Hospital, Newport

Christopher Chick

Royal Gwent Hospital

Brian Anthony Sullivan

Royal Liverpool University Hospital

Richard G McWilliams

Royal Oldham Hospital

Mahesh Kumar

Royal Preston Hospital

Elaine Hewitt

Royal Surrey County Hospital, Guildford

Fuad F Hussain

Royal Victoria Hospital, Belfast

Anton Collins

Sheffield Teaching Hospital

Peter Ellis

Sheffield Teaching Hospital
Peter Kennedy

Sheffield Teaching Hospital

John Bottomley

Sheffield Teaching Hospitals

Trevor Cleveland

Sheffield Teaching Hospital

Peter Gaines

Sheffield Teaching Hospital

Douglas Turner

Shrewsbury \& Telford Hospital NHS Trust

David Hinwood

South Manchester University Hospital NHS Foundation

Trust

Raymond Joel Ashleigh

Southampton General Hospital

David Thompson

Southend Hospital

Andrew Tanqueray

Southern General Hospital, Glasgow

Keith Osborne

St George's Hospital, London

Anna-Maria Belli

St Richard's Hospital, Chichester

Briony Burns

St Richards Hospital

Christopher Young

Stirling Royal Infirmary

Nikolas Arestis

Stirling Royal Infirmary

Emma Beveridge

Torbay Hospital

Peter Kember

Torbay Hospital

Richard Seymour

University Hospital Wales, Cardiff

Andrew Wood

University Hospital, Birmingham Jonathan

David Hopkins

University Hospitals of Leicester NHS Trust

Keith Blanshard

Victoria Infirmary, Glasgow

Andrew Downie

West Suffolk NHS Trust

Vinod Shenoy

Wexham Park Hospital, Slough

Mark Charig

Wythenshawe Hospital, South Manchester

Jonathan Tuck

York Hospital

Niall Warnock 


\section{Contributing Centres and Numbers of Patients Enrolled}

Frequency

Addenbrookes Hospital

11

Aintree Hospital

Altnagelvin

Ayr Hospital

Barts and the Royal London Hospital

Bradford Teaching Hospitals Foundation Trust

Churchill Hospital, Oxford

City Hospital, Birmingham

Colchester General Hospital

Cumberland Infirmary

Derbyshire Royal Infirmary

Derriford Hospital Plymouth

Diana, Princess of Wales Hospital,

East Sussex Hospitals NHS Trust

Freeman, Newcastle Upon Tyne Hospitals NHS Trust

Frimley Park Hospital

Gartnavel General Hospital

Glan Clwyd Hospital-North Wales

Hairmyres Hospital

Harrogate Health Care NHS Trust

Hull Royal Infirmary

Ispwich Hospital

John Radcliffe Hospital, Oxford

Kingston Hospital NHS Trust

Leeds Teaching Hospitals Trust

Leicester Royal Infirmary Hospital

Lister Hospital, Stevenage

Manchester Royal Infirmary

Medway Maritime Hospital

Mid Yorkshire Trust

Midstaffs NHS Foundation Trust

New Cross Hospital, Wolverhampton

Norfolk and Norwich

North Bristol Hospitals

Northampton General Hospital

Northern General Hospital

Papworth Hospital

Princess Royal University Hospital

Queen Alexandra, Portsmouth

Queen Elizabeth, Gateshead

Royal Berkshire NHS Foundation Trust

Royal Bolton Hospital

Royal Bournemouth Hospital

Royal Cornwall Hospital Trust

Royal Gwent Hospital
Table a continued

\begin{tabular}{|c|c|}
\hline & Frequency \\
\hline Royal Liverpool University Hospital & 13 \\
\hline Royal Oldham Hospital & 10 \\
\hline Royal Preston Hospital & 6 \\
\hline Royal Surrey y Hospital & 3 \\
\hline Royal Victoria Hospital, Belfast & 103 \\
\hline Sheffield Teaching Hospital & 97 \\
\hline Shrewsbury and Telford Hospital NHS Trust & 7 \\
\hline South Manchester University Hospital NHS Foundation & 3 \\
\hline Southampton General Hospital & 3 \\
\hline Southend Hospital & 12 \\
\hline Southern General Hospital & 2 \\
\hline St Georges Hospital, London & 51 \\
\hline St Richards Hospital, Chichester & 20 \\
\hline Stirling Royal Infirmary & 5 \\
\hline Tameside Hospitals Foundation NHS Trust & 1 \\
\hline The Rotherham NHS Foundation Trust & 22 \\
\hline Torbay Hospital & 9 \\
\hline UHW Cardiff & 1 \\
\hline University Hospital, Birmingham & 13 \\
\hline University Hospitals of Leicester - NHS Trust & 1 \\
\hline Victoria Infirmary, Glasgow & 12 \\
\hline West Suffolk NHS Trust & 8 \\
\hline Wexham Park Hospital & 4 \\
\hline Wirral Hospital Trust & 2 \\
\hline Wythenshawe Hospital & 5 \\
\hline York Hospital & 13 \\
\hline Grand total & 1433 \\
\hline
\end{tabular}

Conflict of interest The authors have no conflicts of interest to declare.

\section{References}

1. White RH (2003) The epidemiology of venous thromboembolism. Circulation 107:I4-I8

2. British Committee for Standards in Haematology Writing group, Baglin TP, Brush J, Streiff M (2006) Guidelines on use of vena cava filters. Br J Haem 134:590-595

3. Keeling AN, Kinney TB, Lee MJ (2008) Optional inferior vena caval filters: where are we now? Eur Radiol 18:1556-1568

4. Yunus TE, Tariq N, Callahan RE et al (2008) Changes in inferior vena cava filter placement over the past decade at a large community-based academic health center. J Vasc Surg 47:157-165

5. Dabbagh O, Nagam N, Chitima-Matsiga R et al (2010) Retrievable inferior vena cava filters are not getting retrieved: where is the gap? Thromb Res 126:493-497

6. Jassar AS, Nicotera SP, Levin N et al (2011) Inferior vena cava filter migration to the right ventricle. J Card Surg 26:170-172 
7. Nazzal M, Chan E, Abbas J et al (2010) Complications related to inferior vena cava filters: a single-center experience. Ann Vasc Surg 24:480-486

8. Kirilcuk NN, Herget EJ, Dicker RA et al (2005) Are temporary inferior vena cava filters really temporary? Am J Surg 190: $858-863$

9. US Department of Health and Human Services. US Food and Drug Administration (2010) Medical devices. http://www.fda. gov/MedicalDevices/Safety/AlertsandNotices/ucm221676.htm. Accessed 01 April 2012

10. http://www.mhra.gov.uk/Publications/Safetywarnings/Medical DeviceAlerts/CON2030710. Accessed 1 April 2012

11. Geisbüsch P, Benenati JF, Peña CS et al (2011) Retrievable Inferior Vena Cava Filters: Factors that Affect Retrieval Success. Cardiovasc Intervent Radiol DOI: 10.1007/s00270-011-0268-x

12. Yunus TE, Tariq N, Callahan RE et al (2008) Changes in inferior vena cava filter placement over the past decade at a large community-based academic health center. J Vasc Surg 47:157-165

13. Helling TS, Kaswan S, Miller SL, Tretter JF (2009) Practice patterns in the use of retrievable inferior vena cava filters in a trauma population: a single-center experience. J Trauma 67: 1293-1296
14. Lee L, Taylor J, Munneke G et al (2012) Radiology-led Followup System for IVC Filters: effects on Retrieval Rates and Times. Cardiovasc Intervent Radiol 35:309-315

15. Lynch FC (2011) A method for following patients with retrievable inferior vena cava filters: results and lessons learned from the first 1,100 patients. J Vasc Interv Radiol 22:1507-1512

16. Turba UC, Arslan B, Meuse M et al (2010) Günter tulip filter retrieval experience: predictors of successful retrieval. Cardiovasc Intervent Radiol 33:732-738

17. Durack JC, Westphalen AC, Kekulawela S et al (2012) Perforation of the IVC: rule rather than exception after longer indwelling times for the Günther Tulip and Celect retrievable filters. Cardiovasc Intervent Radiol 35:299-308

18. Yamagami T, Tanaka O, Yoshimatsu R, Miura H, Nishimura T (2010) Venous thromboembolism after removal of retrievable inferior vena cava filters. Cardiovasc Intervent Radiol 33:74-79

19. PREPIC Study Group (2005) Eight-year follow-up of patients with permanent vena cava filters in the prevention of pulmonary embolism: the PREPIC (Prevention du Risque d'Embolie Pulmonaire par Interruption Cave) randomized study. Circulation 19(112):416-422 